\title{
Evaluation of Consumers' Preference to the Brands of Beverage by Means of ERP Pre-comprehension Component
}

\author{
Mohammadali Nazari \\ Ph.D in Neuroscience \\ Dept. Psychology. Faculty of Education and psychology \\ University of Tabriz \\ Tabriz, Iran \\ E-mail address: nazaripsycho@yahoo.com \\ Toktam Amanzadeh Oghaz* \\ Dept. of biomedical engineering \\ Azad University \\ Mashhad, Iran \\ E-mail address:toktam.amanzadeh@gmail.com \\ Corresponding Author
}

\author{
Seyed Amir Amin Yazdi \\ Associate Professor of Psychology \\ Dept. Psychology. Faculty of Education and Psychology \\ Ferdowsi University of Mashhad \\ Mashhad, Iran \\ E-mail address: yazdi@um.ac.ir
}

\author{
Zohreh Gholami Doborjeh* \\ Dept. Psychology. Faculty of Education and psychology \\ Ferdowsi University of Mashhad \\ Mashhad, Iran \\ E-mail address: zohre.gholami68@gmail.com \\ Corresponding Author \\ Javad Salehi Fadardi \\ Associate Professor of Psychology \\ Dept. Psychology. Faculty of Education and Psychology \\ Ferdowsi University of Mashhad \\ Mashhad, Iran \\ E-mail address: j.s.fadardi@ferdowsi.um.ac.ir
}

\begin{abstract}
Because of the critical role of emotional and unconscious processes in consumers' decision making, understanding the human brain and neural performance scope varied to better understanding the behavior and predict the consumers' decisions. In this regard, the combination of interdisciplinary studies in the fields of cognitive science has led to the creation of neuromarketing. Neuromarketing is a field of marketing research that studies consumers' sensorimotor, cognitive, and affective response to marketing stimuli.

Objective: The aim of this study was to investigate the role of N1 component of Event-Related Potential (ERP) in measuring consumers' preferences in the face of the brand beverages.

Methods: 26 subjects in the age range of 18 to 26 years old (13 males, mean age $=24.40, S D=1.34$ and 13 females, mean age $=$ 22.60, $\mathrm{SD}=2.87$ ) were examined, for equalizing of subjects' context and increasing their attention, a short story was told to choose a drink. The designed task was displayed and simultaneously the event-related potentials (ERPs) were recorded. The results of the ERP data were evaluated by statistical analysis of repeated measurement ANOVA to check individual brand preferences to the products, in 2 categories (familiar - unfamiliar).

Results: A large significant difference has been seen in N1 component amplitude in occipital lobe for familiar logos than unfamiliar ones which refers to a pre-comprehension brain activity.
\end{abstract}

Conclusion: changes for N1 in occipital lobes showed significant larger amplitude especially in right site of brain that it can be considered as an effective factor in predicting the preference of consumers.

Keywords- neuromarketing; event related potentials (ERP); preference; prediction; n1 component; pre-comprehension brain activity

\section{INTRODUCTION}

In recent years an eruption in the innovation of neuroscientists has been occurred to directly study cortical activities of brain in different fields. The psychological and physiological sciences have been quick to imply such techniques to make huge progress in our understanding of the cognition and emotion in decision making process. Most social sciences have yet to apply neuroimaging as a standard tool or procedure for research [14]. Also, traditional marketing has concentrated on the value and competitive advantages of a product or service, contemporary marketing takes a comprehension approach by also considering the purchasing process and the retail store atmosphere to evoke a positive shopping experience [7]. Neuromarketing is a new application of the neuros-scientific approach to human behavior in the market context. Rather than simply trying to use science to better understand the decision-making 
processes of individuals, neuromarketing studies test subjects' reactions to certain stimuli, which are then recorded with the aim of revealing consumer preferences. The results of these trials can potentially predict differences in thought processes being deployed by consumers that might not necessarily be observable with behavior.

Neuromarketing has revealed significant new information about human preferences and emotional responses by measuring the brain activation when customers view and evaluate different products or logos [14]. Different techniques are used in neuromarketing; Such as the positron emission tomography (PET), the functional magnetic resonance imaging (fMRI), the electroencephalography (EEG), the magnetoencephalography (MEG) and the galvanic skin response (GSR). Even if most of these techniques remain expensive and unavailable, the use of the EEG and the event related potentials (ERPs) is more convenient and inexpensive.

Although P300 component of ERPs in several recent researches on neuromarketing field has been excessively inquired, early components which happen before comprehension process have not assessed sufficiently.

Also many previous studies have demonstrated that the visual N1 component is larger for attended-location stimuli than for unattended-location stimuli. This difference is observed typically only for tasks involving a discrimination of the attended-location stimuli, suggesting that the N1 wave reflects a discrimination process that is applied to the attended location [9]. Due to inquire consumer preferences, in this research we have assessed occipital region to investigate the amplitude of $\mathrm{N} 1$ component as a precomprehension stimulation.

In this article we suggest studying neuromarketing through event related potential (ERPs); we tried to investigate the role of N1 component of ERP on consumers' preferences in the face of the brand beverages.

The exploration of neural circuits aimed at identifying a preference towards a brand has been the center of research that made neuromarketing better known.

McClure et al. (2004) have published the results of a study of two sodas of different brands (Coke and Pepsi). The results of the study have surprised researchers and a large public and have created a big sensation.

The "branding" plays a key role in the mechanism of preference. This directly influences the buying behavior and loyalty [15]. One of the methods which is typically employed as means of evaluating an individual preference between products is brand familiarity.

In neuromarketing studies, brand familiarity and product preference have been correlated with neural activity [11]. Evidence has been found linking the medial prefrontal cortex with both brand familiarity and product preference [3]. Although, comprehension involvement of brain regions have been researched excessively, influential features which appear before cognition and preference to the brands is not sufficiently present.

\section{METHOD(PARTICIPANTS)}

Twenty-six right-handed volunteers (13 men, 13 women) participated in the current research. All had normal or corrected-to-normal vision, and reported no neurological abnormalities. All testing procedures were performed in "Hamrah Neuropsychiatric Center" of Tabriz, Iran.

\section{A. Stimuli}

A total of $8 \log$ os of brands were used as the stimulus set. Although the logos contained verbal/lexical information, we did not consider this information and just concluded according to familiar and unfamiliar categories of logos.

The images were a widely known or familiar brand (e.g., such as the coca cola) and unknown or unfamiliar brand (e.g. such as the Ayda cola) in two different categories: Four beverages' brand and four beer's brand.

\section{B. Procedures}

This task which was designed according to the oddball paradigm was divided into three blocks. Each trial block began with the presentation of the target logo for 200 milliseconds to remind that which logo required a manual response (which was the neutral stimulus). The duration of each stimulus was $200 \mathrm{msec}$, and the interval between the stimuli was randomly varied between 1300 and $1500 \mathrm{msec}$. The target logo was appeared 28 times in each block and each of the 8 none-target logos were presented 14 times, with the different order of presentation in random way between the three blocks and the total number of presenting

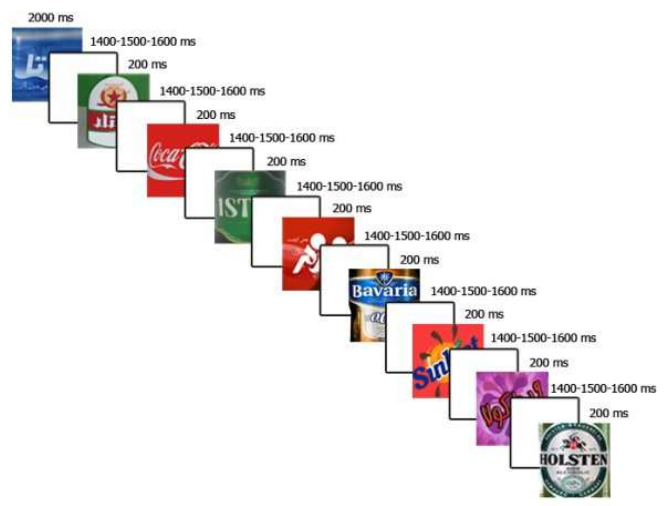

FIGURE I. THE PRESENTING LOGOS AND DURATION OF STIMULI AND TIME INTERVALS

Stimuli were presented on a monitor controlled by a PC using the Mitsar stimulus presentation system (psytask), also manual responses to the target were made by pressing a mouse button which was varied randomly for participants as to press the left or right key to decrease the effect of hemisphere dominance, (counterbalanced). As an initial instruction, participants had been asked to observe the logos on the screen and make a manual response to the target as soon as possible. For equalizing the subjects' context and increasing their attention, before starting the task a short story was told to choose a drink from the 8 none-target logos. It is illustrated in fig1. 


\section{ELECTROPHYSIOLOGICAL RECORDING}

Scalp potentials were recorded from 19 electrodes mounted in a custom elastic cap in configuration with the standard " $10-20$ " location system. All EEG activity was recorded by an amplifier (Mitsar Instruments) with a band pass of $0.1-30 \mathrm{~Hz}$, and digitized on-line at a sampling rate of 250 per second. All electrode impedances were kept below 5 $\mathrm{k} \Omega$. Off-line ICA method was used to correct artifacts. The resulting single-subject ERPs were then used to derive the group averaged waveforms for display and analyses.

\section{RESULTS}

Grand-averaged ERP waveforms for familiar logos, unfamiliar logos and all logos are shown in Fig 2, and mean amplitudes across occipital location and conditions are reported in Table 1. N1 component was calculated on preattended time window in 100-250 milliseconds after stimulus for the mentioned two conditions; familiar/unfamiliar. Statistical analyses of ERP data were analyzed by repeated measures ANOVA (RANOVA); familiar logos versus unfamiliar logos (fam/unfam), and left versus right electrode positions $(\mathrm{L} / \mathrm{R})$ as within subject factors.

Table I MEAN AMPLITUDE $(\mu \mathrm{V})$ OF GROUP-AVERAGED ERPS FOR FAMILIAR, UNFAMILIAR AND ALL LOGOS

\begin{tabular}{ccc} 
Scalp location: occipital & \multicolumn{3}{c}{ Time window: 100-250 } \\
& OL & OR \\
Familiar logos & -3.42 & -4.37 \\
Unfamiliar logos & -3.03 & -3.68 \\
All logos & -2.91 & -3.49 \\
\hline
\end{tabular}

RANOVA revealed a significant main effects of electrode position $(\mathrm{F}=11.45, \mathrm{p}=0.01)$; the amplitude of right occipital is larger than left site.

Main effect of familiarity/unfamiliarity $(\mathrm{F}=3.51, \mathrm{p}=0.01)$ and the interaction effect of electrode position and familiarity/unfamiliarity were significant $(F=4.66, p=0.04)$.

\section{DISCUSSION}

According to studies that have been performed on neuromarketing field, most of the researches had widely considered to the P3 component of ERP. In the present study, we intended to investigate whether the pre-comprehension component (such as N1 in occipital lobe) might be related to preference to logos.

In most of the times the visual N1 component is largest over the occipital region [4] or the inferior temporal regions [1]. Larger amplitude of N1 is typically obvious in stimulus discrimination tasks $[12,13]$, but the shorter amplitude refers to stimuli which are presented at short intervals. The higher amplitude of this component is related to enhance processing of the attended region of brain [8].

Contrary to the unfamiliar brand names and logos, the processing duration for familiar logos is performed faster in the brain by causing less brain activity in working memory region and more involvement in emotional areas.
Changes in N1 amplitude of occipital lobe can affect anterior areas widely. As a result, the amplitude of P3 and other late components in central and frontal lobes would definitely be affected by early components and it proves the significant role of pre-comprehension attended regions in prediction of preference.

\section{CONCLUSION}

As this study reveals, N1 can be evoked by visual external stimuli which is possible by presenting different logos' characters. The more superficial the information of logos be, seem more familiar to the customers and attract their attention. Companies would be able to utilize N1 component to verify preference of customers.

\section{REFRENCES}

[1] Bokura, H. Yamaguchi, S., \& Kobayashi, S. (2001) Electrophysiological correlates for response inhibition in a $\mathrm{Go} / \mathrm{NoGo}$ task. Clinical Neurophysiology, 112, 2224-2232.

[2] Coull, J. (1998). Neural correlates of attention and arousal; Insights from electrophysiology, functional neuroimaging and psychopharmacology. Progress in Neurology, 55, 343-361.

[3] Damasio, A. R. (1996). The somatic marker hypothesis and the possible functions of the prefrontal cortex. Philosophical transactions of the Royal Society of London, Series B, Biological sciences, 351, 1413-1420.

[4] Hopf, J.-M., Vogel, E., Woodman, G., Heinze, H.-J., \& Luck, S. (2002). Localizing visual discrimination processes in time and space. Journal of Neurophysiology, 88, 2088-2095.

[5] Kenning P, Plassmann H (2005) Neuroeconomics: an overview from an economic perspective. Brain Res. Bull., 67: 343-354.

[6] Lee N, Broderick AJ, Chamberlain L (2007). What is neuromarketing? A discussion and agenda for future research. Int. J. Psychophysiol., 63:199-204

[7] Levy, M., College, B. (2009). Retailing Management. Barton A. Weitz, University of Florida. ISBN: 0073381047

[8] Luck, S. J., \& Hillyard, S. A. (1995). The role of attention in feature detection and conjunction discrimination: An electrophysiological analysis. International Journal of Neuroscience, 80, 281-297.

[9] Luck, S. J., Hillyard, S. A., Mouloua, M., Woldorff, M. G., Clark, V. P., \& Hawkins, H. L. (1994). Effects of spatial cuing on luminance detectability: Psychophysical and electrophysiological evidence for early selection. Journal of Experimental Psychology: Human Perception and Performance, 20, 887-904.

[10] Vogel, E.K. \& Luck, S.J. (2000). The visual N1 component as an index of a discrimination process.Psychophysiology, 37, 190-203.

[11] McClure SM, Li J, Tomlin D, Cypert KS, Montague LM, Montague PR (2004) Neural correlates of behavioral preference for culturally familiar drinks. Neuron, 44: 379-387.

[12] Mangun, G.R. \& Hillyard, S.A. (1990). Allocation of visual attention to spatial location; Eventrelated brain potentials and detection performance. Perception and Psychophysiology, 47,532-550.

[13] Mangun, G.R., Hillyard, S.A., \& Luck, S.J. (1993). Electrocortical substrates of visual selective attention. In D. Meyer \& S. Kornblum (Eds). Attention and performance 14: Synergies in experimental psychology, artificial intelligence, and cognitive neuroscience (pp. 219-243). MIT Press.

[14] Plassmann, H., Ramsøy, T. Z., \& Milosavljevic, M. (2012). Branding the brain: A critical review and outlook. Journal of Consumer Psychology, 22(1), 18-36. doi: http://dx.doi.org/10.1016/j.jcps.2011.11.010

[15] Touhami, Z. O., Benlafkih, L., Jiddane, M., Cherrah, Y., Malki, O., \& Benomar, A. (2011). Neuromarketing: Where marketing and neuroscience meet. African Journal of Business Management Vol.5 (5), pp. 1528-1532. DOI:10.5897/AJBM10.729. 



FIGURE II. GROUND AVERAGE WAVEFORMS FOR FAMILIAR, UNFAMILIAR AND ALL LOGOS. 